\title{
“EU ME SENTI ASSIM, NO MEIO DOS PROFESSORES DE GEOGRAFIA E DE PORTUGUÊS, EU ALI PEQUENININHA NO MEIO DOS DOIS, DOIDA PARA APRENDER JUNTO": reflexões sobre o desenvolvimento profissional na construção de oficinas de Matemática no contexto da Educação Integral
}

\author{
Luan Martins de Oliveira ${ }^{l}$ \\ Edmilson Minoru Torisu2 \\ Claudia Starling Bosco 3
}

\section{RESUMO}

Este artigo tem como objetivo desvelar indícios de desenvolvimento profissional de uma professora de Matemática, ao longo do processo de elaboração e implementação de oficinas de Matemática voltadas à Educação Integral, em parceira com o pesquisador, a partir das reflexões realizadas pela professora. A pesquisa empírica foi realizada no primeiro semestre de 2017, em uma escola pública do interior de Minas Gerais, Brasil. Os dados foram coletados por meio de observações, anotações em diário de campo e entrevistas com a professora. Os resultados da análise dos dados mostraram possibilidades de mudanças, evidenciadas por: um aumento de seu comprometimento; mudanças nas formas de agir e pensar, sobretudo, naquilo que se refere ao trabalho em parceria, ao papel dos alunos na sala de aula e, muito importante, ao conceito de oficina na Educação Integral; aumento de sua autonomia e de sua confiança para novas propostas.

Palavras-chave: Educação Integral. Desenvolvimento Profissional do professor de Matemática. Oficinas.

\footnotetext{
1 Mestre em Educação Matemática pela Universidade Federal de Ouro Preto. Professor da Rede Pública Estadual de Ensino de Minas Gerais. Orcid iD: http://orcid.org/0000-0001-92603631. Email: Ivanmartins55555@gmail.com

2 Doutor em Educação pela Universidade Federal de Minas Gerais (linha de pesquisa: Educação Matemática). Professor Adjunto do Departamento de Educação Matemática (UFOP) e Coordenador/Professor do Programa de Pós-graduação em Educação Matemática (UFOP). Orcid iD: http://orcid.org/0000-0001-7383-387X. Email: edmilson@ufop.edu.br

3 Doutora em Educação pela Universidade Federal de Minas Gerais. Professora Adjunta de Didática e do Programa de Pós-graduação Mestrado Profissional da Faculdade de Educação (UFMG). Orcid iD: http://orcid.org/0000-0003-1496-3695. E-mail: claudiastarling@hotmail.com
} 


\title{
“I FELT SO 'SMALL' WHEN AROUND MY GEOGRAPHY AND PORTUGUESE COLLEGUES, I' M REALLY 'CRAZY' TO LEARN WITH THEM": reflections on the professional development in the construction of Mathematical workshops in the context of Integral Education
}

\begin{abstract}
This article aims to unveil evidence of professional development of a Mathematics teacher throughout the process of elaboration and implementation of Mathematics workshops directed to the Integral Education in partnership with the researcher, based on the reflections made by the teacher. The empirical research was carried out in the first half of 2017 at a public school in the interior of Minas Gerais, Brazil. Data were collected through observations, field diary notes and interviews with the teacher. The results of the data analysis showed possibilities for changes, evidenced by: an increase in their commitment; changes in the ways of acting and thinking, especially in what refers to work in partnership, the role of students in the classroom and, very important, the concept of workshop in the Integral Education; increase their autonomy and confidence for new proposals.
\end{abstract}

Keywords: Integral Education. Professional Development of the Mathematics teacher. Workshops.

\section{"ME SENTÍ TAN 'PEQUEÑO' ENTRE LOS PROFESORES DE LA GEOGRAFÍA Y PORTUGUÉS, 'LOCO' QUE APRENDER DE ELLOS": reflexiones sobre el desarrollo profesional en la construcción de talleres de matemáticas en el contexto de la Educación Integral}

\section{RESUMEN}

Este artículo tiene como objetivo desvelar indicios de desarrollo profesional de una profesora de Matemáticas a lo largo del proceso de elaboración e implementación de talleres de Matemáticas orientadas a la Educación Integral en asociación con el investigador, a partir de las reflexiones realizadas por la profesora. La investigación empírica fue realizada en el primer semestre de 2017 en una escuela pública del interior de Minas Gerais, Brasil. Los datos fueron recolectados por medio de observaciones, anotaciones en diario de campo y entrevistas con la profesora. Los resultados del análisis de los datos mostraron posibilidades de cambios, evidenciadas por: un aumento de su compromiso; cambios en las formas de actuar y pensar, sobre todo en lo que se refiere al trabajo en asociación, al papel de los alumnos en el aula y, muy importante, al concepto de taller en la Educación Integral; aumento de su autonomía y de su confianza en nuevas propuestas.

Palabras clave: Educación Integral. Desarrollo Profesional del profesor de Matemáticas. Talleres. 


\section{INTRODUÇÃO}

A Educação Integral (EI) tem sido um dos eixos presentes em discussões e pesquisas que envolvem a formação docente por ser um tema presente nos programas e projetos educacionais. Tratar do desenvolvimento profissional em contextos profissionais, envolvendo a El torna-se um grande desafio, pois envolve articular a formação docente em um determinado contexto profissional, considerando suas especificidades.

Este artigo tem como objetivo desvelar indícios de desenvolvimento profissional de uma professora de Matemática, ao longo do processo de elaboração e implementação de oficinas de Matemática, em turmas do $6^{\circ}$ ano do Ensino Fundamental, voltadas à El, em parceira com o pesquisador, a partir das reflexões realizadas pela professora.

A pesquisa aqui retratada foi realizada nos anos de 2016 e 2017 é fruto de uma parceria entre o pesquisador e uma professora de matemática que atua em uma escola estadual, localizada no interior do estado de MG.

Historicamente, de acordo com Cavaliere (2010), as primeiras ideias em favor da El surgiram na primeira metade do século $X X$, fortemente marcadas por ações de cunho educativo promovida pela igreja católica, passando pelo movimento anarquista e pelo movimento denominado integralista. Ao longo dos anos, até os dias atuais, a concepção de El sustentou diferentes discursos que estão ligados a diferentes projetos de sociedade. Aliás, foram problemas sociais que emergiram ao longo das décadas os responsáveis pelo surgimento de uma perspectiva educacional que reorganizou o currículo, ampliou significativamente as dimensões, os tempos, os espaços e as oportunidades formativas. Em boa medida, a El passou a representar uma educação na qual o contexto sociocultural dos educandos assume uma posição de destaque na sala de aula e na escola (CAVALIERE, 2002).

A El visa ao desenvolvimento de crianças e jovens em suas dimensões cultural, afetiva, cognitiva, emocional e física, por meio de experiências educativas e projetos coletivos compartilhados com o contexto educacional (MOLL, 2009). Atualmente, a El possui novos vieses metodológicos, políticos e 
epistemológicos, principalmente, ligados à extensão da carga horária de permanência do estudante na escola (PESTANA, 2014) que surge como consequência da precarização do ensino, que começa na escolarização primária no século XX, na qual era possível encontrar nas escolas pouca estrutura, redução da carga horária, multiplicação dos turnos e baixa qualidade dos professores.

Entretanto, estudos mostram (LIMA, 2015; SILVA 2018) que a El tem contribuído para importantes mudanças na escola, seja na relação entre os pares, na construção de espaços formativos entre os professores ou na reflexão dos docentes sobre a própria prática.

Especificamente, em relação ao planejamento da ação docente, as oficinas são consideradas uma alternativa interessante para atender às novas demandas do ensino que possam realmente efetivar transformações sociais, sendo que a interdisciplinaridade ganha relevância nestas discussões. Isso corrobora as ideias de Vieira e Volquind (2002) para quem a oficina de ensino é um tempo e um espaço destinados a oferecer situações de aprendizagem ligadas ao dia a dia, em que o processo pedagógico, a reflexão teoria-prática e a relação interdisciplinar se integralizam.

É neste contexto que este artigo se insere, articulando as discussões sobre El e a formação docente, apresentando dados e reflexões sobre a parceria entre pesquisador e professora na construção de oficinas de Matemática, que favoreceu o desenvolvimento profissional dos professores e do pesquisador envolvidos.

Neste artigo, apresentamos análises dos dados, enfatizando situações em que podemos evidenciar sinais de desenvolvimento profissional, vivenciados pelos participantes no proceso de produção e de implementação das oficinas pela professora de Matemática em turmas do $6^{\circ}$ ano.

Na próxima seção, apresentaremos uma breve discussão teórica a respeito do desenvolvimento profissional do professor e do professor de Matemática. Em seguida, apresentaremos os aspectos metodológicos da 
pesquisa, alguns dados e suas análises para, ao final, responder ao objetivo proposto neste artigo e tecer algumas considerações a respeito do estudo.

\section{DESENVOLVIMENTO PROFISSIONAL DOCENTE}

Selecionar o tema desenvolvimento profissional como eixo de análise torna-se fundamental, pois como argumenta Marcelo Garcia (1999), a formação docente é um processo contínuo e está atrelado aos diferentes contextos de vivência do professor. Consideramos que o desenvolvimento profissional docente abrange as situações pessoais e profissionais do sujeito, a formação inicial e as que foram construídas ao longo de sua trajetória. Conforme Day (2001), envolve as vivências espontâneas e aquelas que foram, intencionalmente, construídas individual ou coletivamente.

Podemos considerar como evidência de aspectos ligados ao desenvolvimento profissional quando o professor, por exemplo, demonstra ter construído conhecimentos sobre a própria ação pedagógica.

Passos et al. (2006) afirmam que, na literatura, muitos autores consideram o desenvolvimento profissional como sinônimo de formação e que outros consideram que a formação é parte do desenvolvimento profissional, sendo este um processo mais amplo que tem início desde o ingresso do profissional na escola.

No primeiro caso, o desenvolvimento profissional ocorre como resultado da participação do professor naquilo que temos denominado formação inicial e continuada.

A formação inicial refere-se à formação obtida na graduação que prioriza os conhecimentos da Matemática acadêmica (no caso do professor de Matemática) e os conhecimentos didático-pedagógicos, de disciplinas como prática de ensino e estágio supervisionado. A formação continuada refere-se a momentos de atualização de conteúdos aprendidos na formação inicial e ocorre, na maioria das vezes, por meio de cursos que priorizam a transmissão de técnicas e conhecimentos considerados relevantes para o professor em exercício (PASSOS et al., 2006). 
No segundo caso, o desenvolvimento profissional é visto como um processo e, nessa perspectiva, seu conceito tem "[...] uma conotação de evolução e continuidade que, a nosso ver, supera a tradicional justaposição entre formação inicial e formação contínua dos professores" (MARCELO GARCIA, 2009, p. 9). Para o estudo do desenvolvimento profissional do professor sob essa ótica, é necessário que se tenha, de sua vida, uma visão holística, a partir da qual vários aspectos são considerados. Não são priorizados somente conhecimentos que ele adquire por meio de cursos muitas vezes impostos por agentes externos. Deve-se considerá-lo, ele próprio, como agente de suas mudanças, com desejos, aspirações, frustrações, muitas vezes, influenciadas pelo meio sociocultural, no qual está inserido e pelas suas condições de vida. Essas palavras corroboram aquelas de Charlot (2005 apud PASSOS, 2006, p. 106) quando o autor considera que

\begin{abstract}
Investigar o Desenvolvimento Profissional do professor, portanto, vai além da análise dos conhecimentos que adquire ao longo da vida profissional. Implica interpretá-lo, também, como sujeito com desejos, intenções, utopias, desilusões, que sofre os condicionamentos de seu contexto histórico-cultural. Ou seja, um sujeito de relação com o mundo, com as práticas escolares, com os conhecimentos institucionais, com as políticas públicas, com o seu tempo, com os outros e consigo mesmo.
\end{abstract}

Um fator importante que interfere diretamente para que ocorra 0 desenvolvimento profissional do professor é seu comprometimento. Naturalmente, o desenvolvimento profissional pode ocorrer ainda que 0 professor não esteja comprometido, mas pode ser catalisado por um maior comprometimento do profissional e se tornar, de acordo com Ponte (1994; 1995), o principal ingrediente para mudanças na vida do professor.

Por outro lado, há fatores que atrapalham e, por vezes, impedem o desenvolvimento profissional do professor. Segundo Stein (1998), citado por Ferreira (2003), alguns desses fatores são a carga horária extensa e a preferência de boa parte dos professores por trabalhar em isolamento. Além disso, Day (1999) destaca que essas situações de dificuldade evidenciam-se na "[...] intensificação do seu trabalho, na ampliação da prestação de 
contas burocrática e contratual, na diminuição de recursos e no aumento do sistema administrativo" (DAY, 1999, p. 24) enquanto Jesus e Santos (2004) acrescentam, ao rol de fatores que desestimulam o professor rumo ao seu desenvolvimento profissional, a baixa remuneração. Ao fenômeno resultante de todos esses fatores que podem minar o desenvolvimento profissional do professor Day (1999) denomina erosão da autonomia do professor.

Contudo, ainda que haja empecilhos a seu desenvolvimento, o professor comprometido com seu trabalho sentirá, em muitos momentos de sua vida profissional, a necessidade de caminhar para a mudança. Isso ocorre muitas vezes, quando o professor reflete sobre suas experiências e, como consequência dessa reflexão, se inquieta e passa a desejar mudanças.

Dessa forma, o exercício da reflexão parece ter papel importante para que o professor se desenvolva. A discussão em torno desse assunto não é recente. John Dewey, em livro publicado em 1900, já salientava o exercício da ação reflexiva por professores. Anos mais tarde, Donald Schön passou a ser referência no assunto após publicar, em 1983, o livro intitulado "O profissional reflexivo". Nele, Schön traz à baila a discussão de alguns tipos de reflexão, dos quais destacamos a reflexão-na-ação e a reflexão-sobre-aação.

A reflexão-na-ação, como o próprio nome anuncia, ocorre durante a ação e diz respeito a processos de tomada de decisão por parte dos professores envolvidos no processo de ensinar. Centra-se na identificação e na solução rápida de problemas imediatos. Em sala de aula, esse tipo de situação é recorrente. A todo momento, os professores são instados a resolver situações com as quais estão, ou não, acostumados. De acordo com Ponte (1994; 1995), duas coisas podem ocorrer para resolver esse conflito: acomodação, na qual o professor decide pela solução mais simples, como, por exemplo, ministrar a aula preparada e ignorar a reação dos estudantes, ou refletir de forma rápida sobre a situação conflituosa e mudar os rumos da aula. Essa tomada de decisão, que precisa ser rápida, 
dado o contexto, tem relação com aquilo que Schön (1998, p. 29) denomina talento artístico profissional, que são "tipos de competência que os profissionais demonstram em certas situações da prática que são únicas, incertas e conflituosas" e que emergem espontaneamente.

A reflexão-sobre-a-ação é um processo que ocorre fora da ação, mas tendo-a como objeto principal para "análise, reconstrução e reformulação da prática, no sentido de planejar o ensino e a aprendizagem em termos futuros. Ao contrário da reflexão-na-ação, este processo cria oportunidades para conversar com outros sobre o ensino" (DAY, 1999, p. 57). Esse compartilhamento de ideias que pode suscitar profícuas discussões entre professores ou entre professor e outros profissionais tende a ser bastante útil. De acordo com Day (1999, p. 69 - 70), "refletir na e sobre a ação resultará, em última análise, numa aprendizagem limitada, caso seja levada a cabo de forma isolada". Daí a importância do trabalho em parceria.

Vale ressaltar que o ato de refletir é inerente ao ser humano. Todos nós refletimos sobre algo em algum momento da vida. Mas a defesa em favor da prática reflexiva teve, de acordo com Zeichner (2008), papel importante como reação ao paradigma vigente por muito tempo no campo da Educação, por meio do qual os professores eram vistos como técnicos que "meramente fazem o que outras pessoas, fora da sala de aula, querem que eles façam, e contra modelos de reforma educacional do tipo 'de cima para baixo', que envolvem os professores apenas como participantes passivos" (ZEICHNER, 2008, p. 5).

Em contrapartida, o professor reflexivo assume papel ativo na formulação dos propósitos e finalidades de seu trabalho, reforçando a importância da autonomia docente. A "reflexão" também significa que a produção de conhecimentos novos sobre ensino não é papel exclusivo das universidades e o reconhecimento de que os professores também têm teorias que podem contribuir para 0 desenvolvimento para um conhecimento de base comum sobre boas práticas de ensino (ZEICHNER, 2008, p. 5). 
Dessa forma, refletir assume uma importância crucial no processo de mudança de postura do professor diante de sua ação, que contribui para o seu desenvolvimento profissional. O professor, após refletir sobre sua prática pode se sentir incomodado e desejar mudanças, favorecendo a construção de novas concepções sobre o que é ensinar, saberes específicos de sua profissionalidade.

Entendemos que o desenvolvimento profissional é um processo contínuo influenciado por vários aspectos do emaranhado social no qual o professor está inserido. Torna-se necessário, portanto, olhar para o professor com lentes ampliadas, compreendendo sua trajetória formativa, que nos permitam estabelecer conexões que existem entre sua vida dentro e fora da escola. Isso poderá nos dar pistas de fatos, de situações e de condições que impulsiolnam seu Desenvolvimento Profissional. Um olhar mais acurado sobre a ação docente nos permitirá, ainda, perceber indícios de desenvolvimento, como seu envolvimento ao longo do processo.

No presente estudo, além de tentar identificar esses indícios por meio dos pressupostos teório-metodológicos que sustentam nossa investigação, tentamos promover momentos de reflexão em parceria, nos quais professora e pesquisador puderam discutir e avaliar suas ações e as possiveis transformações rumo a um caminho de mudanças na ação docente. A compreensão do próprio trabalho pedagógico realizado pelo professor para a melhoria da prática surge como resultado de processos reflexivos. De acordo com Zeichner (2008), "[...] o processo de compreensão e de melhoria de seu próprio ensino deve começar da reflexão sobre sua própria experiência e que o tipo de saber advindo unicamente da experiência de outras pessoas é insuficiente" (ZEICHNER, 2008, p. 539).

Desta maneira, o desenvolvimento profissional como um processo formativo docente pode ser mais ou menos ampliado, a partir das experiências que vivencia e como ele reflete sobre a trajetória vivida.

No que segue, apresentamos aspectos metodológicos que sustentam a discussão proposta neste artigo. 


\section{CAMINHO METODOLÓGICO}

Esta pesquisa, de cunho qualitativo, teve como principal objetivo, desvelar indícios de desenvolvimento profissional de uma professora de Matemática, ao longo do processo de elaboração e implementação de oficinas de Matemática voltadas à El, em parceira com o pesquisador, a partir das reflexões realizadas pela professora.

A pesquisa empírica foi realizada durante o primeiro semestre de $2017^{4}$, em uma escola estadual, localizada no interior de Minas Gerais. Os participantes da pesquisa foram o próprio pesquisador, 25 anos, licenciado em Matemática, a professora Júlia, 35 anos, efetiva de Matemática do ensino regular desde 2016, mas com experiência de quatro anos na El. Júlia é formada em Administração Pública e complementou os estudos em Matemática. É importante registrar que Júlia é considerada pelos pares, pela direção da escola e pelos estudantes uma profissional comprometida e muito querida pela comunidade escolar. Outros professores também participaram das oficinas, contribuindo para o trabalho: o professor de Geografia e a professora de Língua Portuguesa. Embora os estudantes da turma da professora Júlia, a maioria oriunda de bairros mais carentes da cidade, não fossem nosso foco, eles participaram em vários momentos da pesquisa, sobretudo quando da implementação das oficinas.

Dada à polissemia da palavra oficina, torna-se necessário definirmos o seu significado neste estudo. Atualmente, a palavra oficina se incorporou às perspectivas de ensino, em especial no Brasil, onde se ligou às concepções de El. Alguns exemplos dessa incorporação estão presentes nos textos do documento orientador das ações da El do Estado de Minas Gerais, de 2017, e nas orientações do Manual Operacional da El do Programa Mais Educação, de 2014. Ambos os documentos trazem orientações similares quanto à sua utilização que orientam os professores para que atendam às necessidades e às expectativas dos alunos, aproximando as atividades desenvolvidas à realidade dos estudantes e, além disso, incentivam os

\footnotetext{
${ }_{4}^{4}$ Esta investigação foi aprovada pelo Comitê de Ética (CEP) da Universidade Federal de Ouro Preto via registro CAAE 61396116.3 .0000 .5150$.
} 
professores a contemplarem conhecimentos diversificados em seu planejamento, que vão além da sua disciplina (BRASIL, 2014; MINAS GERAIS, 2017). Sobre oficinas, Vieira e Volquind (2002) enfatizam que:

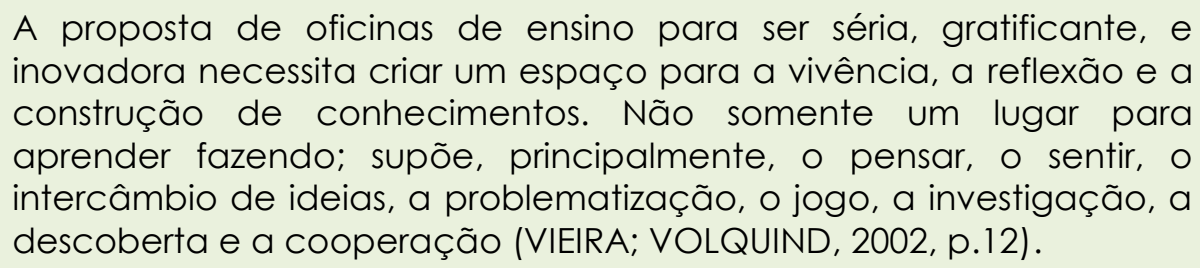

Nesse estudo, que envolveu a professora de Matemática Júlia, o pesquisador e outros professores que contribuíram para o trabalho, foram construídas oficinas na perspectiva de Vieira e Volquind (2002) e de Candau (1995). Estes autores compreendem as oficinas como um espaço de construção coletiva do conhecimento, de análise da realidade, de confronto e de troca de experiências, que podem ser de vários tipos: cognitivas, afetivas e culturais. A construção coletiva de conhecimentos está fortemente embasada no conceito de interdisciplinaridade.

Pensar a interdisciplinaridade como um elemento fundamental que emerge do trabalho colaborativo no contexto escolar, envolvendo professores de diversas disciplinas na construção das oficinas, requer considerar sua importância na fragmentação disciplinar. Vários autores, como Libâneo (2013) reafirmam que em uma construção de trabalho numa perspectiva interdisciplinar há mudanças de paradigmas em relação ao ensino, considerando os saberes e as experiências dos estudantes, a articulação entre teoria e prática e o diálogo entre vários conhecimentos, propiciando o trabalho coletivo.

Durante 0 processo formativo vivenciado pela professora de Matemática em parceria com o pesquisador no contexto da El, foram criadas as seguintes oficinas:

1 - Oficina do Banco Imobiliário

Esta oficina foi dividida em duas partes. A primeira contou com a participação, além da professora Júlia e do pesquisador, dos professores de Geografia e de Português. A contribuição do professor de Geografia se deu 
quando ele explorou, com a participação dos estudantes, temas como: centro e periferia, conceituação do uso social dos bairros, valorização dos bairros a partir dos usos, conceito de paisagens, conceito de bairros residenciais e comerciais. A professora de português, utilizando slides, apresentou as regras do jogo e ajudou os estudantes a interpretá-las.

As contribuições desses dois professores serviram, em alguma medida, para mitigar o caráter quase exclusivamente lúdico atribuído pela maioria das pessoas ao uso de jogos em sala de aula. Permitiu que os estudantes percebessem novas possibilidades de exploração do jogo. Ainda nessa primeira parte, Júlia explorou assuntos da Matemática como cálculo mental, operações básicas e conceituação do sentido horário e anti-horário. Essa foi uma estratégia da professora para preparar os estudantes para a segunda parte, na qual eles deveriam tomar várias decisões nas quais a Matemática teria papel importante.

Na segunda parte, os estudantes, utilizando as regras e as ideias exploradas na primeira parte, realizaram o jogo utilizando o tabuleiro customizado para a cidade de Ponte Nova, MG (ver figura 1).

FIGURA 1 - Tabuleiro do Banco Imobiliário

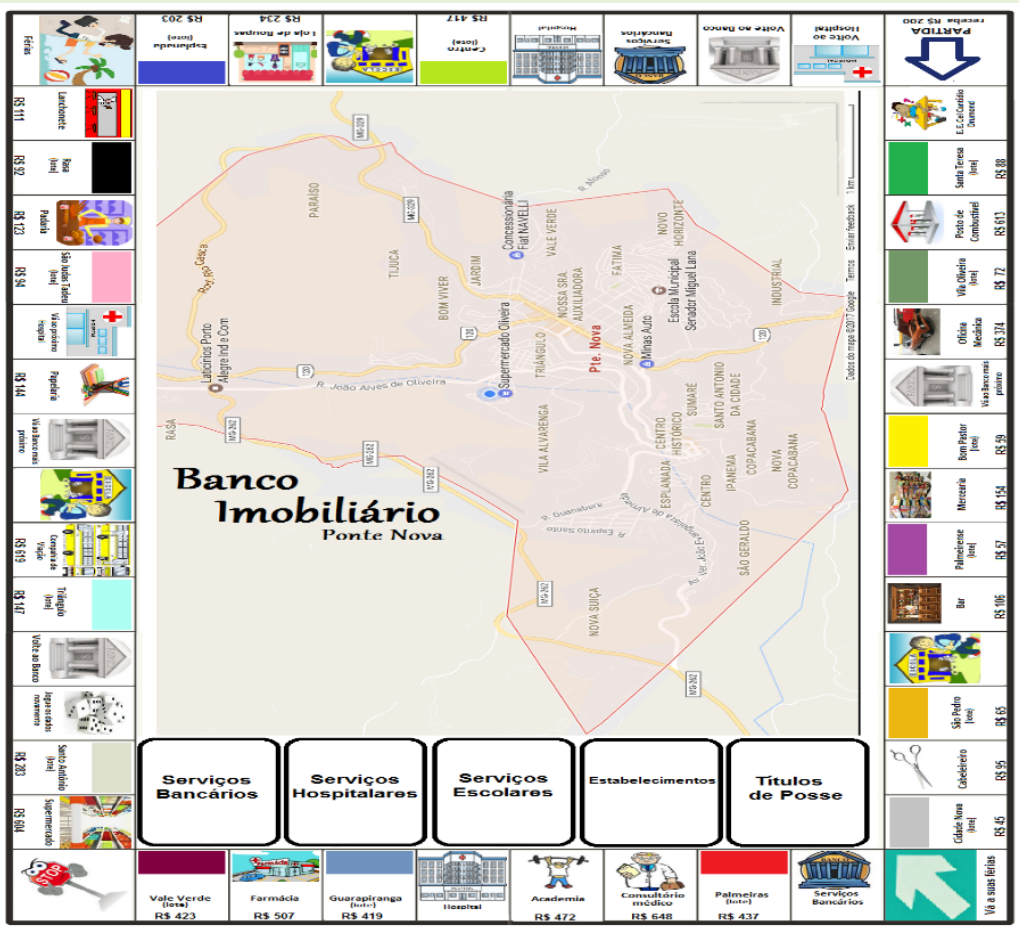

Fonte: autor (2017). 


\section{2 - Oficina da Beleza Rara}

Esta oficina foi idealizada pela professora Júlia, que a dividiu em três etapas. No primeiro, ela levou os estudantes para um salão repleto de espelhos e explorou assuntos relacionados à beleza pessoal. Na segunda, convidou a dona de um salão de beleza para conversar com os estudantes a respeito de higiene pessoal: cuidados com cabelos, pele. Na terceira e úmtima etapa, os estudantes construíram, juntamente com Júlia, um kit de higiene pessoal, utilizando caixas de sapato com 0 formato de paralelepípedo. Júlia aproveitou, então, para explorar com os estudantes conceitos como área e volume, vértices, arestas, faces.

3 - Oficina do Mercadinho

A oficina do Mercadinho foi composta por várias suboficinas. A primeira, introdutória, contou com a participação da professora Júlia, do pesquisador e de mais dois professores, um deles, responsável pelas atividades denominadas de Economia Solidária. Nessa suboficina, os professores exploraram curiosidades relacionadas à organização de um supermercado como, por exemplo: por que alguns produtos são escolhidos ficar em destaque, em frente às entradas dos corredores ou da própria loja? Como são escolhidos os produtos que ficarão nas prateleiras do alto, do meio e de baixo? Além disso, trouxeram à discussão o fato de, nos bairros menores, haver pequenas mercearias. Ainda nessa primeira suboficina, a professora explorou o conhecimento dos estudantes acerca de sólidos geométricos presentes nos supermercados na forma de embalagens. Aproveitando as informações contidas nas embalagens, Júlia explicou as principais unidades de massa (quilo e grama) e unidades de capacidade (litro e mililitro).

Como desdobramento da primeira suboficina, foram elaboradas mais quatro suboficinas: O sistema monetário; Organização dos setores do nosso supermercado; Orçamento e Indo às compras.

Podemos notar que todas as oficinas oportunizaram aos estudantes aprendizagem matemática, mas não somente. A contextualização presente em todas elas permitiu a exploração de outros aspectos necessários ao 
desenvolvimento dos estudantes (e professores) como, o pensar, o sentir, o intercâmbio de ideias, a investigação, a descoberta, a contrução coletiva do conhecimento, a análise da realidade e as trocas de experiências, colocados em relevo por Vieira e Volquind (2002) e Candau (1995).

Neste contexto de produção e de implantação das três oficinas, para a coleta de dados utilizamos observações em sala, anotações no diário de campo e entrevistas com a professora Júlia. As entrevistas foram realizadas em quatro etapas: uma inicial, antes da elaboração em parceria das oficinas pedagógicas, algumas durante o processo de elaboração das oficinas, uma após a aplicação de cada oficina e outra no final, ou seja, após a elaboração e aplicação de todo processo de pesquisa.

As entrevistas foram semiestruturadas, à exceção daquelas feitas durante a realização nas oficinas, que tiveram um caráter mais informal, "pouco estruturadas, sem um fraseamento e uma ordem rigidamente estabelecida para as perguntas, assemelhando-se muito a uma conversa" (ALVEZ-MAZZOTTI, GEWANSDSZNAJDER, 1998, p. 168). Essas entrevistas se consolidaram como momentos importantes de reflexão em parceria entre pesquisador e professora, no intuito de avaliar o processo e no que ele poderia contribuir para melhorias de sua prática. A reflexão conjunta sobre as ações trouxe melhores resultados, já que, de acordo com Day (1999, p. 69-70), "refletir na e sobre a ação resultará, em última análise, numa aprendizagem limitada, caso seja levada a cabo de forma isolada".

Os dados coletados de diferentes instrumentos possibilitaram a criação de categorias de análise que mostraram como a produção e a implementação de oficinas em parceria entre pesquisador e professora, contribuindo para o desenvolvimento profissional dos envolvidos.

\section{DADOS E RESULTADOS}

Como já mencionado, a coleta de dados foi realizada por meio de observações em sala de aula, entrevistas e conversas informais com a professora, antes, durante e depois da produção e da implementação das oficinas. Na primeira entrevista, realizada antes do início da elaboração das 
oficinas, pudemos conhecer um pouco mais a professora Júlia. Os resultados obtidos contribuíram para compreender um pouco mais sobre as concepções da professora ao longo do trabalho.

A professora, com quatro anos de experiência na $\mathrm{El}$, vivenciou situações desafiadoras em relação à gestão da classe e à forma de conduzir suas turmas, ao relatar que:

Quando eu comecei trabalhar, a primeira coisa que a inspetora falou comigo foi: lugar de aluno é na sala de aula. Se eu estiver na escola e você mandar um aluno para fora da sala, eu vou devolvê-lo (Trecho da Entrevista - Profa Júlia 06/03/2017).

Manter a organização da sala parecia ter se tornado uma regra a ser cumprida por Júlia em suas aulas. Nas observações de sala de aula, percebemos que este aspecto estava muito presente. Essa crença talvez esteja associada à tão disseminada ideia de que um bom professor é aquele que mantém a disciplina em sala de aula, aqui compreendida como "manter alunos calados". Uma estratégia, muito utilizada por Júlia para manter os alunos quietos era utilizar o quadro. Ela nos disse:

Sempre gostei muito mais do quadro porque eu consigo prender muito mais o aluno no quadro do que com o livro, questão de disciplina (Trecho da Entrevista - Profa Júlia 06/03/2017).

Práticas como essa que, de alguma forma, resolvem conflitos de forma rápida, por surtir o efeito esperado - alunos quietos - e que, por essa razão, passam a ser recorrentes, são denominadas por Yinger (1979, apud DAY, 1999) de rotinas. As rotinas, por surtirem efeito momentâneo na sala de aula, em face de situações que o professor considera complexas, muitas vezes padronizam a forma de agir em sala de aula e podem levar o professor à acomodação, com consequente estagnação. Isso porque, a não reflexão sobre os efeitos dessa ação, ou reflexão-sobre-a-ação, em momento posterior, não permite que as rotinas sejam submetidas a um escrutínio de seu real efeito sobre a aprendizagem dos alunos. 
Com o decorrer do trabalho em parceria na construção das oficinas, um dos indícios evidenciados de desenvolvimento profissional refere-se a este tópico: gestão da sala. Os dados revelam que, mesmo sem perceber/explicitar, a professora começou a considerar a sala de aula como um espaço em que os estudantes não eram simples expectadores. Eles participavam, opinavam e o quadro negro muitas vezes nem era utilizado. Essa nova forma de agir, demonstra uma transformação na maneira como a professora Júlia percebia o espaço da sala de aula, trazendo indícios de desenvolvimento profissional.

Outro tópico que merece destaque é a concepção de oficinas para El que a professora Júlia demonstrou no início do trabalho e após a implementação das oficinas produzidas coletivamente.

A professora Júlia compreendia que a extensão de tempo na El deveria ser utilizada para aulas de reforço, conforme seu relato:

Eu prefiro como era antes, em que sentido, eu tinha mais autonomia antes, por exemplo, não se pode usar o termo reforço, do tempo regular. Usando esse termo reforço, do tempo regular, eu conseguiria pegar as principais dificuldades dos meninos na sala de aula e dar de fato um reforço um estudo dirigido. Lógico que eu não fazia isso toda semana, não fazia isso todo dia, eu fazia isso pré-avaliação deles, entendeu? Ah! É semana de prova, a gente vai estudar. Como é que a gente vai estudar? Aí que entrava a Educação Integral, ensinava os meninos a estudar, a estudar em grupo, a estudar em dupla, individual (Trecho da Entrevista - Profa Júlia 06/03/2017).

Ainda que Júlia estivesse pensando na aprendizagem de seus alunos, aulas de reforço têm um conceito diferente da perspectiva do trabalho com oficinais. Mesmo em suas tentativas para trabalhar com essa proposta, ela não se guiava por nenhum documento orientador oficial ou concepção teórica sobre o que eram as oficinas e como implementá-las em sala de aula, tomando como ponto de partida a busca na Internet. Ao discutir com o pesquisador sobre o processo de construção das oficinas que desenvolvia, Júlia relata que: 
Verdadeiramente falando, tem a internet. Sempre que eu preciso, sempre. Se quero trabalhar a tabuada, eu vou lá na internet. Eu gosto, por exemplo, da Secretaria de Educação do Rio. Eles têm exemplos de oficinas que são feitos no regular que eu acho fantástica. A gente vê experiência e de outros professores que postam blogs ou outras coisas, né? Eu tento algo parecido com a nossa realidade, vou me envolvendo e vou ver se encaixa. Tem é, dia a dia, também acho que é do Paraná, também tem umas coisas muito bacanas (Trecho da Entrevista - Profa ${ }^{a}$ Júlia -06/03/2017).

Estes elementos presentes no relato da professora, contradizem as diretrizes que os documentos oficiais, como o documento orientador, versão 3, do Estado de Minas Gerais (2004, p. 17), apresentam:

Trabalhar oficinas diversificadas requer do professor um amplo conhecimento não só dos macrocampos e suas atividades, mas também da realidade do território que a escola está inserida. Desta forma, a direção escolar deverá orientar os professores para que estas oficinas atendam às expectativas dos estudantes e contribua para a sua formação enquanto cidadão.

Percebemos que não houve um projeto de formação advinda da escola para que os professores pudessem compreender as finalidades e os pressupostos envolvidos na realização de oficinas que ultrapassa o seguir um modelo pré-estabelecido, mas envolvem o trabalho colaborativo na escola, a partir de uma concepção de educação mais transformadora.

fato de a professora se preocupar em sanar as dificuldades dos estudantes e ensiná-los como trabalhar em duplas, grupos ou individualmente, mostra sua preocupação com a aprendizagem dos estudantes para realizarem as avaliações escolares. No entanto, esta estratégia de utilização de oficinas prontas retiradas da internet, sem partilhar com os pares e sem refletir sobre os pressupostos teóricos que sustentam tais atividades, contribuía para que a professora deixasse de experimentar momentos de aprender com os estudantes e com professores de outras disciplinas, em um trabalho realmente interdisciplinar. Segundo Vieira e Volquind (2002), as oficinas são um tempo e um espaço destinados a oferecer situações de aprendizagem ligadas ao dia a dia, em que a 
interdisciplinaridade, o processo pedagógico e a reflexão teoria-prática se integralizam. Isso nos mostra quão importante é, na estruturação das oficinas, considerar a interdisciplinaridade.

Entretanto, ao longo do processo de criação das oficinas, a professora foi descobrindo novas possibilidades para criá-las e tendo interesse em participar do processo de construção, escolhendo temas, sugerindo mudanças e criando oportunidades para participação de outros professores.

Por exemplo, durante a elaboração e a implementação da oficina do Banco Imobiliário, uma adaptação do jogo já existente, Júlia demonstrou interesse em identificar as dificuldades percebidas nos estudantes, sugeriu que a oficina pudesse explorar conteúdos que eles precisariam aprender, como as operações básicas. Percebemos, aqui, outro indício de desenvolvimento profissional, pois Júlia demonstrou interesse em criar oficinas que pudessem atender às especificidades de turma, refletindo sobre a própria prática.

Ainda exemplificando, a partir da construção da oficina Banco Imobiliário, propusemos à professora que, ao invés da cidade do Rio de Janeiro, utilizássemos dados da cidade onde a escola estava localizada. Júlia achou a ideia interessante e sugeriu que o formato do tabuleiro, normalmente, retangular, fosse adaptado para o formato do mapa da cidade. Após algumas tentativas, percebemos que o novo formato dificultaria o jogo e, por isso, mantivemos o formato retangular. No entanto, embora a ideia de utilizar o mapa da cidade não tenha sido efetivada, ela contribuiu para surgimento de uma nova ideia vinda de Júlia: convidar o professor de Geografia para participar da criação da oficina. Isso evidencia outro indício de desenvolvimento profissional, na medida em que a professora Júlia sente a necessidade de novas parcerias, iniciando um desejo de trabalho conjunto. Assim, essa proposta foi muito interessante por duas razões principais: contribuir para explorar novos temas para discussão que não somente aqueles ligados à Matemática e contribuir para iniciar uma prática de trabalhos em parceria com outros professores. Além do professor de Geografia, posteriormente, a professora de Português também 
foi convidada para contribuir para a elaboração e a implementação da oficina.

Assim, o professor de Geografia começou a participar do projeto. Dois momentos de sua participação merecem ser registrados. O primeiro momento trata de como esse professor vislumbrava explorar a oficina com olhar de geógrafo:

[...] Vocês podem ainda verificar porque no bairro São Pedro os aluguéis são muito mais baratos que no Vale Verde [...]. Tem a ver com a proximidade? Tem, mas qual a diferença entre um e outro? [...] Podemos trabalhar essa valorização dos bairros a partir dos usos. Podemos determinar o uso social do espaço e - que agrega valor ao bairro. Por exemplo: é você ter comércio perto, ter supermercado, um serviço importante como a Cemig e a gente discutir essa relação, do espaço e do uso. Poderia fazer um "link" com a questão do conceito de paisagem. Será que os usos interferem em alguma característica específica da paisagem? Em um bairro, por exemplo, residencial, a paisagem possui menos comércios (Trecho do Encontro para elaboração da oficina do Banco Imobiliário- Prof. de Geografia-10/04/2017).

Esse momento demonstra quão rica seria a oficina para discutir com os estudantes, assuntos tão importantes e relacionadas às suas realidades, mas não diretamente ligados à Matemática. Mais que isso, essa fala evidencia que a ideia de Júlia de convidar o professor para participar foi acertada e que ela, não acostumada a trabalhar em parceria estava, em alguma medida, criando espaços de troca no interior da escola. Ela buscou fazer conexões com outros e estabelecer novas parcerias.

Assim, este aspecto do desenvolvimento profissional que estava latente, ou seja, a construção em parceria das oficinas, com participação do pesquisador, professora e outros professores, mostrou-se benéfica por permitir um entrosamento de todos no planejamento do ensino. É um tipo de parceria denominada por Day (1999) de parceria desenvolvimentista, na qual todos os envolvidos aprendem algo, diferente da parceria instrumental, que é imposta. Além disso, Day (1998) menciona que a parceria desenvolvimentista ajuda o professor a desenvolver certo tipo de reflexão 
que permite a análise e a reconstrução de novos planejamentos. Planejar atividades em conjunto também demonstra desenvolvimento profissional e, no caso desse estudo, a preocupação com o planejamento fica evidente na seguinte fala do professor de Geografia, quando ele sugere formas de organizar a oficina com os professores, incluindo a professora de Português, também convidada a participar. O professor de Geografia disse o seguinte:

[...] se a Professora de Português tiver disponibilidade também no finalzinho da aula para alinharmos as ações [...] quando vou trabalhar? Em que momento? [...] era melhor fazer um horário especial onde a gente conseguiria juntar essas turmas em um coletivo e trabalhar em conjunto tipo uma oficina interdisciplinar mesmo. Por exemplo: na hora que a Professora de Português estivesse interpretando a ideia do valor de cada bairro, eu ajudaria na interpretação do uso social, paisagem. Nem que seja um momento coletivo e faça assim: pega os dois sextos anos e aplica (Trecho do Encontro para elaboração da oficina do Banco Imobiliário- Prof. Geografia 10/04/2017).

Após o trabalho em parceria com os professores e o pesquisador, Júlia disse: "[...] eu me senti assim, no meio dos professores de Geografia e de Português, eu ali pequenininha no meio dos dois, doida para aprender junto [...]".

A percepção de que o trabalho em parceria traz aprendizagens, reforça ainda mais a importância desse tipo de organização das atividades na escola, no que se refere, entre outros aspectos, ao desenvolvimento profissional. Consideramos que a fala da professora Júlia evidencia uma reflexão-sobre-a-ação por parte da professora, o que contribui para o seu desenvolvimento e corrobora as ideias de Day (1999) sobre a importância de a reflexão ocorrer em parceria com outros profissionais, ao considerar que "refletir na e sobre-a-ação resultará, em última análise, numa aprendizagem limitada, caso seja levada a cabo de forma isolada" (DAY, 1999, p. 69-70).

A professora Júlia, ao refletir sobre o processo vivenciado em relação às transformações que foram evidenciadas em sua prática pedagóica, sinalizou que: 
[...] já impactou, se não tivesse impactado eu não tinha chamado a moça da beleza rara, uma profissional para ministrar uma palestra, sem antes sentar e planejar com ela, entendeu? Hoje eu não, chamaria ninguém para ensinar aos meus alunos sem conversar com eles antes, sem apresentar os meus alunos, sem falar de fato o que eu quero, entendeu, nem que seja uma conversa por chat, uma troca de e-mails. (Trecho da entrevista que finalizou o processo de pesquisa, em 12 de julho de 2017.)

A reflexão da professora revela uma nítida mudança em relação às concepções de ensino, valorizando a elaboração do planejamento em parceria, ressaltando a importância dos objetivos e finalidades da ação pedagógica e a defesa dos estudantes considerados como atores sociais, distanciando de uma visão tradicional de simples transmissão de conteúdos.

As análises dos dados sugerem indícios de desenvolvimento profissional vivenciados por Júlia no processo de construção das oficinas por meio de reflexão sobre a própria prática docente, como demonstra em seu relato:

[...]. Eu planejei em casa, [...], eu tive que fazer as coisas em casa, pois não tive jeito de fazer na escola, pegar, ler, pensar no que ia falar. [...] ontem não tinha luz, mas eu estava preparada para dar aula mesmo sem luz, pois eu conhecia meu material, eu ia dar oficina sem energia, sem nenhum slide, eu conhecia meu material, eu tenho muito medo, de muita improvisação, mas eu tenho que contar com elas. [...]. Eu tive que parar, sentar, com minha filha no colo, eu tive que estudar para fazer aquilo, e outra, a gente vai pensando, [...] essa questão do insight ela vem muito mais por que, você está ali por dentro do que você está falando, ai vem aquele estalo na hora, neh? Você já sai daqui avaliando. É automático (Trecho do Encontro para elaboração da oficina do Banco ImobiliárioProfa Júlia-28/06/2017).

Esse trecho de fala da professora mostra que o seu comprometimento permitiu a ela planejar melhor as atividades. O planejamento, por sua vez, a fez se sentir mais segura para dar sua aula, mesmo que adversidades pudessem ocorrer. A professora menciona, também, sobre seus insights durante as aulas, o que nos parece como uma reflexão-na-ação. A reflexãona-ação, sozinha, não contribui para uma mudança efetiva da prática, mas acompanhada da reflexão-sobre-a-ação pode potencializar a aprendizagem do professor e, consequentemente, ajudá-lo a caminhar para 
uma mudança efetiva do fazer pedagógico. Comprometimento é um dos fatores que, segundo Ponte $(1994$; 1995) podem levar ao desenvolvimento profissional.

Outro aspecto que, acreditamos, tenha contribuído para o desenvolvimento da professora é aquele relacionado às mudanças e às inovações em sua forma de agir e de pensar a sua prática. Várias reflexões evidenciam este aspecto:

Um exemplo são as aulas que estou dando hoje no sexto ano, o sétimo ano [...]. Já trabalhei com SlideShow em sala de aula [...]. Fiz também, uma avaliação em três dias, [...], então assim eu senti que eles aprenderam muito mais nesses três dias de avaliação, [...] De fato eu tive um aprendizado com os meninos, que eu nunca tive até então (Trecho do Encontro para elaboração da oficina do Banco Imobiliário-Profa Júlia 15/05/2017).

Ontem, com base na quarta, eu já fiz com que os meninos sentassem em uma forma que eu gostaria que eles sentassem para evitar a indisciplina e essa questão de colocar os alunos maiores como monitores ajudou mesmo, isso falando da prática. Segundo ponto, essa questão da indagação, ontem o tempo todo, não dei nada pronto para eles, indaguei o tempo todo, [...], minhas intervenções foram muito mais assim, do que de fato mostrar a resposta pronta [...] (Trecho do Encontro para elaboração da oficina do Banco Imobiliário- Profa Júlia 28/06/2017).

Júlia demostra como ela adotou novas ações, incluindo novas formas de avaliar os alunos, valorizá-los em sala de aula atribuindo a eles papel de protagonistas do processo de aprendizagem.

Em uma conversa sobre planejamento, a professora relatou/mencionou, questionou, afirmou, problematizou:

Sabe um negócio que eu pensei que podemos colocar na nossa oficina? A questão da permuta. Talvez nós consigamos montar, dentro do supermercado, um espaço onde eles possam trazer coisas, a origem da moeda, porque antigamente, quando não tinha dinheiro, havia trocas, entendeu? Eu pensei também trabalhar esse conceito do sistema monetário [...]. Nosso Banco Imobiliário nós trabalhamos o tempo todo com o dinheiro e não falamos da origem da moeda [...] Teria que ser antes de etiquetar, porque 
dar preço é utilizar o sistema monetário. [...] (Trecho do Encontro para elaboração da oficina do Banco ImobiliárioProfa Júlia - 07/06/2017).

O objetivo inicial da oficina tornou-se, a partir dessas ideias de Júlia, algo muito mais ambicioso e rico para os estudantes. Trabalhar os conceitos de permuta e de sistema monetário torna-se relevante para que os estudantes se apropriem de conhecimentos importantes para compreender o mundo em que vivemos, como por exemplo, conhecimentos sobre a História do dinheiro e seus usos sociais, ligados ao consumismo e às desigualdades sociais.

\section{CONSIDERAÇÕES FINAIS}

À guisa de finalização desse artigo, retomamos o seu objetivo principal, que foi desvelar indícios de desenvolvimento profissional de uma professora de Matemática, ao longo do processo de elaboração e implementação de oficinas de Matemática em turmas do $6^{\circ}$ ano do Ensino Fundamental, voltadas à El em parceira com o pesquisador, a partir das reflexões realizadas pela professora. Então, afinal, que indícios foram encontrados?

O processo de criação de oficinas em parceria gerou conflitos na prática pedagógica da professora, contribuindo para que ela, a partir de um trabalho em parceria, pudesse repensar sua própria ação docente, como relata:

Cada momento que nós passamos juntos construindo isso, se torna também uma prática no regular, isso para mim é quase uma formação, eu vejo muito mais isso como uma aula, eu te falei isso, que você me cutucou que você me incomodou demais, você me incomodou mesmo [...] estou vendo isso muito mais como um período de formação (Trecho da entrevista final - Profa Júlia - 12/072017).

Essa declaração da professora, na entrevista realizada ao final do processo, demonstra como a proposta gerou incômodos e desafios mas, ao mesmo tempo, provocou um desejo por mudanças, que aqui consideramos 
indício de desenvolvimento profissional. Nesse sentido, concordamos com Pehkonen e Tôrner (1999), citados por Ferreira (2003, p.39), quando eles consideram que "a mudança não pode acontecer sem uma perturbação nos pensamentos e ações dos professores".

Alem do desejo por mudanças, o aumento do comprometimento da professora, traduzido pelo seu esforço para participar de todo o processo de criação e implementaçã das oficinas, também pode ser considerado como indício de desenvolvimento profissional (PONTE, 1994). Vejamos duas respostas dadas por Júlia que evidenciam esse comprometimento.

Estudei até uma hora da manhã.

[...] Eu tive que parar, sentar, com minha filha no colo, seja lá como que foi, eu tive que estudar para fazer aquilo, e outra, a gente vai pensando, [...] (Entrevista realizada após aplicação da Oficina do Mercadinho Profa Júlia - 28/06/2017)

Estas respostas revelam algumas formas utilizadas por Júlia para driblar situações do dia a dia que pudessem impedí-la de participar da elaboração/implementação das oficinas, superando obstáculos para se desenvolver, estudar e aprender.

As mudanças na forma de agir da professora, sobretudo, naquilo que se refere ao seu fazer pedagógico, são outro indício de seu desenvolvimento profissional.

Um exemplo são as aulas que estou dando hoje no sexto ano, o sétimo ano [...] (Trecho da entrevista realizada após a oficina do Banco Imobiliário- Profa Júlia 15/052017).

[...] Hoje não chamaria ninguém para conversar com meus alunos, sem antes conversar com eles, sem falar de fato o que eu quero, nem que seja por um chat, e-mail, inicialmente tem que ter uma prévia (Trecho da entrevista final Imobiliário- Profa Júlia - 12/072017)

[...] Já impactou. Se não tivesse impactado eu não tinha chamado a profissional da beleza (Oficina de Beleza 
Rara), sentando e planejando com ela [...] (Trecho da entrevista final - Profa Júlia - 12/07/2017)

As falas da professora são exemplos de como a sua participação nas oficinas impactou a sua forma de agir e de pensar na/a sala de aula. A criação de uma oficina (Beleza Rara) de forma independente, sem a ajuda do pesquisador, pode ter sido resultado de sua maior confiança em trabalhar com essa proposta, a partir do que havia aprendido durante a construção das oficinas em parceria e é um exemplo de mudança. Além de evidenciar uma mudança na forma de agir da professora, a criação da oficina de forma independente revela aumento da autonomia da professora, que também pode ser compreendido como indício de desenvolvimento profissional.

Antes do encontro com o pesquisador, as experiências de trabalhos, em parceria com outros professores eram parcas para Júlia. No decorrer do trabalho de criação e implementação das oficinas, sobretudo, nos momentos em que houve contribuição/participação dos professores de Geografia e Português, Júlia pôde perceber quão ricas podem ser essas parcerias, rendendo ganhos de conhecimento inestimáveis para todos os envolvidos no processo. Essa ressignificação do trabalho em parceria, que o desnuda e traz à luz muitas de suas potencialidades, antes naõ percebidas pela professora, é, para nós, indício de desenvolvimento profissional.

Novas pesquisas podem ser realizadas com o objetivo de investigar possibilidades para o desenvolvimento profissional do professor durante a criação de oficinas. Uma proposta interessante, nesse sentido, seria a proposição de um curso de formação continuada ou de extensão universitária que levasse às escolas de Educação Integral um formato diferente de aprendizagem, no qual o professor não fosse receptor passivo daquilo que se pretende ensiná-lo, mas fosse protagonista e participasse ativamente dos momentos de criação e execução de oficinas, por exemplo. Além da parte prática, discussões em torno das diretrizes para a Educação 
Integral seriam bem-vindas. Elas serviriam como um norte para o trabalho em parceria.

Isso poderia trazer, a cada curso, uma identidade própria, que respeitasse o contexto social no qual se inserem a escola e todos os seus atores: professores, estudantes, direção, pais e suas vivências. Essa proposta vai ao encontro do que Júlia disse em uma entrevista:

[...] viesse aqui, conhecesse a realidade da escola, sentasse com o professor, para que ele entendesse. Eu fico pensando, se a gente tivesse, igual tem você comigo, tivesse um com português [...]. Os questionamentos que você fez, me incomodaram. Quer dizer que eu me propus a fazer melhor que eu estava fazendo. Pode ter certeza, porque se não tivesse me incomodado, eu não teria mudado muita coisa que eu mudei (Trecho da Entrevista final - Profa. Júlia - 12/07/2017).

Essa fala da professora critica, ainda que de forma não intencional, os cursos de formação que surgem prontos para os professores, sem levar em conta as particularidades de cada contexto. Como resultado disso, eles nõo acrescentam muito ao repertório de conhecimento dos professores.

Esta pesquisa permitiu mostrar a importância das investigações na área de Formação/Desenvolvimento Profissional de Professores que ensinam Matemática, em particular, professores que atuam na Educação Integral. O processo de construção e implementação das oficinas em parceria, constituiu-se como um espaço de aprendizagem para todos que participaram.

\section{REFERÊNCIAS}

ALVES-MAZZOTI, A. J.; GEWANDSZNAJDER, F. O planejamento de pesquisas qualitativas. In: ALVES-MAZZOTI, A. J.; GEWANDSZNAJDER, F. O método nas ciências naturais e sociais: pesquisa quantitativa e qualitativa. São Paulo: Pioneira, 1998. p. 147-178.

BRASIL. Estatuto da criança e do adolescente e legislação correlata. Lei $n$. 8069 de 13 de julho de 1990 e legislação correlata, 12. Ed. Brasília: Edições Câmara, 2014. 
CANDAU, V. Oficinas pedagógicas de direitos humanos. Petrópolis: Vozes, 1995.

CAVAlIERE, A. M. Anísio Teixeira e a Educação Integral. Paideia, v. 20, n. 46, p. 249-259, 2010.

CAVALIERE, A. M. Educação Integral: uma nova identidade para a escola brasileira. Educação e Sociedade, v. 23, n. 81, p. 247-270, 2002.

DAY, C. Desenvolvimento profissional de professores: os desafios da aprendizagem permanente. Porto - Portugal: Porto Editora, 1999.

FERREIRA, A. C. Metacognição e desenvolvimento profissional de professores de Matemática: uma experiência de trabalho colaborativo. Tese (doutorado em Educação). Universidade Estadual de Campinas, Campinas/SP, 2003.

LIBÂNEO, J.C. Organização e gestão da escola: teoria e prática. 6 ed. São Paulo: Heccus Editora, 2013.

LIMA, S. B. M. Programa Mais Educação nas Escolas do Campo:

oportunidade de aprofundamento dos princípios da Educação do Campo?

- O caso do Colégio Estadual Vale da Esperança, Formosa/GO. Dissertação (Mestrado em Educação). Universidade de Brasília, Brasília/DF, 2015.

MARCELO GARCIA, C. Desenvolvimento profissional docente: passado e futuro. Revista de Ciências e Educação, v. 8, p. 7-22, 2009.

MARCELO GARCIA, C. Formação de Professores: para uma mudança educativa. Porto: Porto Editora, 1999.

MINAS GERAIS. Documento orientador, versão 3, do Estado de Minas Gerais, 2004.

MOLL, J. Educação Integral: texto referência para o debate nacional. Brasília: MEC/SECAD, 2009.

PASSOS, C. L. B.; NACARATO, A. M.; FIORENTINI, D.; MISKULIN, R. G.; GRANDO, R. C.; GAMA, R. P.; MELO, M. D. Desenvolvimento profissional do professor que ensina Matemática: uma meta-análise de estudos brasileiros. Quadrante, v. 15, n. 1, p. 193-219, 2006.

PESTANA, S. F. P. Afinal, o que é Educação Integral? Revista Contemporânea de Educação, v. 9, n. 17, 24-41, 2014.

PONTE, J. P. O desenvolvimento profissional do professor de Matemática.

Educação e Matemática, n. 31, p. 9-12, 1994. 
PONTE, J.P. Perspectivas de deenvolvimento profissional de professores de Matemática. CIEFCUL, Universidade de Lisboa, Portugal, 1995.

SCHÖN, D. A. Educando o profissional reflexivo: um novo design para o ensino e a aprendizagem. Porto Alegre: Artmed, 1998.

SILVA, M. C. Educação Integral e proteção social no contexto de uma escola pública de tempo integral. Dissertação (Mestrado em Educação).

Universidade Federal do Estado do Rio de Janeiro. Rio de Janeiro/RJ, 2018.

VIEIRA, E.; VOLQUIND, L. Oficinas de ensino: o que? Por quê? Como? Porto Alegre: Edipucrs, 2002.

ZEICHNER, K. M. Uma análise crítica sobre a reflexão como um conceito estruturante na formação docente. Educação e Sociedade, v. 29, n. 103 , 2008.

Recebido em: 14 de fevereiro de 2019 Aprovado em: 03 de julho de 2019 